\title{
UBER, LA SUBORDINACION Y LAS FRONTERAS DEL DERECHO DEL TRABAJO. ALGUNAS IDEAS PARA DELIMITAR
}

\author{
UBER, SUBORDINATION AND THE BORDERS OF LABOR LAW. \\ SOME IDEAS TO DELIMITATE
}

\author{
BORIS MUÑOZ GARCÍA* \\ Universidad Nacional Andrés Bello, Chile
}

\begin{abstract}
Resumen: El concepto de subordinación o dependencia es utilizado, hasta ahora, como la herramienta clave para determinar al sujeto protegido por el Derecho del Trabajo. Desde los inicios de la disciplina, sus contornos se ajustaron al perfil del empleado que, debido a su minusvalía principalmente de tipo económica, requería de algún tipo de protección heterónoma. Sin embargo, sucede que las formas de trabajo no se desarrollan ni evolucionan en función de las categorías jurídicas ya creadas, sino que atienden a otros factores, de variado orden, como la sociología, la economía y, especialmente, la tecnología. No en vano, se habla de los períodos del fordismo o del toyotismo para referir distintos modelos de trabajo y, no en vano también, el propio origen del Derecho Social se enlaza estrechamente con la Revolución Industrial. Hoy asistimos a un nuevo fenómeno, el de la economía digital o gig economy, sostenido en un desarrollo tecnológico de ritmo vertiginoso que ha dado un vuelco a la vida en general y, en particular, al modo en que se organiza y ejecuta el empleo. El caso más simbólico de estos nuevos modelos es el de Uber. En tal contexto el Derecho del Trabajo se ve, una vez más, en la necesidad de evaluar las fórmulas que utiliza para determinar los alcances de su esfera protectora cual es, justamente el propósito de este artículo. Concretamente, el objetivo es analizar algunas de las herramientas de que se vale el laboralismo, utilizando como referencia el concepto de subordinación, que es la más tradicional. Tal estudio pretende dar cuenta de la recepción legislativa, doctrinaria y jurisprudencial de estas fórmulas enfrentadas a situaciones como las que plantea este nuevo modelo productivo, sin perder de vista la situación del ordenamiento nacional.
\end{abstract}

Palabras claves: Uber economy; Derecho del Trabajo; subordinación.

\begin{abstract}
The concept of subordination or dependence is, until now, used as the key tool to determine the subject protected by Labor Law. From the beginning of the discipline, its contours were adjusted to the profile of the employee who, due to his disability, mainly of the economic type, required some kind of heteronomous protection. However, it happens that forms of work do not develop or evolve in terms of the legal categories already created, but rather address other factors of varying order, such as sociology, economics, and
\end{abstract}

\footnotetext{
* Abogado y Licenciado en Ciencias Jurídicas y Sociales de la Facultad de Derecho de la Universidad de Chile. Magíster en Derecho del Trabajo y Seguridad Social por la Universidad de Talca y la Universidad de Valencia. Correo electrónico: boris.munoz@unab.cl.
}

Este trabajo fue recibido el 11 de enero de 2018 y aprobado el 27 de marzo de 2018. 
especially technology. It is not in vain that we speak of periods of Fordism or Toyotism to refer to different models of work and, not in vain too, the very origin of Social Law is closely linked with the Industrial Revolution. Today we are witnessing a new phenomenon, that of the digital economy or gig economy, sustained in a technological development with a vertiginous rhythm that has given a turn to life in general and, in particular, to the way in which the work is organized and executed. The most symbolic case of these new models is that of Uber. In this context, Labor Law is once again in the need to evaluate the formulas used to determine the scope of its protective field, which is precisely the purpose of this article. Specifically, the objective is to analyze some of the tools that laborism is worth, using as reference the concept of subordination, which is the most traditional. This study intends to give an account of the legislative, doctrinal and jurisprudential reception of these formulas, faced with situations such as those posed by this new productive model, without losing sight of the situation of the national order.

Keyword: Uber economy; Labor Law; legal subordination.

\section{1.- Introducción}

El afán cautelar del Derecho del Trabajo conlleva una serie de cargas y costos para la actividad productiva. Por lo mismo, no es de extrañar la constante y perseverante intención empresarial de buscar los medios que le permitan disminuir, si es que no derechamente eludir, algunas de las obligaciones que nacen de toda relación laboral. Para tal efecto, las fórmulas utilizadas son las figuras contractuales que no se encuentran protegidas por este ordenamiento y que, en consecuencia, se rigen por las disposiciones del derecho común, civil o comercial. Se trata de una de las manifestaciones de la llamada huida del Derecho del Trabajo, fenómeno sobre el que se ha analizado y escrito desde hace ya bastante tiempo (Baylos, 2000: 68).

El prototipo de la prestación de servicios ubicada fuera de los límites del ordenamiento laboral es el trabajo autónomo. Por lo mismo, entre las consecuencias que ha acarreado esta huida del Derecho del Trabajo se cuenta una importante masificación de este formato de labores. El afán de crecimiento personal y económico, por otra parte, así como el anhelo de mayor libertad y falta de control, sin duda ensalzado por el capitalismo, ha significado una fuerte revalorización en la actualidad de este tipo de prestación de servicios (Caamaño, 2004: 68).

Parte de la doctrina se ha planteado la interrogante sobre si aún es válida, en los tiempos que corren, la dicotomía entre trabajo dependiente protegido y trabajo autónomo desregularizado (Calvo, 2005: 45-49). La cuestión se torna relevante en tanto la calificación tiene por objeto distribuir la protección laboral a un verdadero juego de «todo o nada»: la diferencia es radical entre quedar o no amparado por las normas protectoras del Derecho del Trabajo.

En la actualidad esta discusión ha reflotado ya que el mundo del trabajo se encuentra, otra vez, ante un nuevo fenómeno que amenaza con remecer sus cimientos tradicionales. Se trata de la economía virtual que, dicho en términos simples, se refiere al intercambio de bienes y servicios por medio de internet (Raso, 2016 b: 68).

Insertos de lleno en la era de la sociedad de la información, cada día aparecen nuevas formas de trabajo cuyos contornos no encuadran necesariamente con los límites tradicionalmente utilizados por el Derecho Laboral. Dentro de este género es posible diferenciar una serie de formatos y modelos. De ellos, nos interesa el llamado trabajo sobre demanda a través de aplicaciones - works on demand via apps - cuyo caso más representativo es el de la llamada Uber Economy, que trata de una forma de prestación de servicios en que el operario y el usuario se conectan on-line, pero donde el servicio se presta off-line (Raso, 2016 a: 70). 
La empresa Uber, central en este trabajo y paradigma de este nuevo modelo económico (al punto que se utiliza su nombre para denominarlo) opera actualmente en 75 países. Según información que la propia empresa compartió con Bloomberg, durante 2016 sus registros alcanzaron la cifra de 20.000 millones de dólares, con ingresos netos que habrían superado los 6.500 millones en ese mismo período ${ }^{1}$. En Chile, Uber opera desde el año 2014 y ya tiene presencia en 17 ciudades y 14 regiones del país ${ }^{2}$.

Se dice de este nuevo modelo de negocios, que genera oportunidades de empleo a grupos marginados como jóvenes, migrantes, trabajadores a tiempo parcial y jubilados, a quienes resulta dificultoso el acceso al mercado de trabajo; a la vez que permite flexibilizar el empleo y el emprendimiento. Se advierte, sin embargo, que puede provocar situaciones de precariedad y simulación laboral (Parlamento Europeo, 2017).

El presente análisis tiene como propósito aportar a la discusión sobre el Derecho del Trabajo y sus herramientas de acción frente a este nuevo escenario, bajo la premisa que su objetivo esencial es tutelar a los trabajadores que se encuentran en la posición más débil. Para ello, luego de dar cuenta de la constante y prácticamente intrínseca necesidad de evolución que caracteriza a nuestra disciplina, así como de las fórmulas que se han utilizado y se utilizan para la consecución de sus fines, se analizarán algunas de esas opciones enfrentadas con los desafíos que depara esta nueva forma de trabajo. Se destinará un especial lugar a la más reciente jurisprudencia comparada sobre el tema, así como a las posturas doctrinarias que ya se han elaborado. Obviamente, el enfoque asume como punto relevante la situación de nuestro ordenamiento nacional, a fin de evaluar si está o no en condiciones de hacer frente con eficiencia, eficacia y certeza jurídica a este nuevo fenómeno. Se plantea, como hipótesis, que la herramienta tradicionalmente utilizada por el Derecho del Trabajo, esto es, el concepto de subordinación, deja flancos abiertos y, por mucho que sea flexible, no alcanza por sí sola para cumplir con los objetivos protectores de la disciplina con el rigor científico que ostenta tener.

\section{2.- El Derecho del Trabajo, su propósito, alcance y herramientas}

\section{1.- El afán protector del Derecho del Trabajo y su herramienta predilecta: la subordinación}

Como se acaba de indicar, es una premisa de este análisis la naturaleza esencialmente protectora del Derecho del Trabajo. Se comparte que, como dice Baylos, el propósito de esta disciplina es constituir un sistema de garantías para los trabajadores que, por pertenecer a una determinada clase social, se encuentran materialmente en la necesidad de realizar una actividad productiva en favor de otro (Baylos, 1991: 52). Kahn-Freund, en el mismo sentido, señala que el Derecho del Trabajo existe para contrapesar la desigualdad inherente en toda relación laboral, la que se manifiesta en un disímil poder de negociación entre trabajador y empleador (Kahn-Freund, 1998: 45-65).

\footnotetext{
1 Uber levanta el velo sobre sus resultados de negocio. Adlatina.com. Publicación diaria. Disponible en: goo.gl/Z7juYj.

${ }^{2}$ Uber comienza a operar en cinco nuevas ciudades y ya llega a 14 regiones desde Arica a Punta Arenas. Diario Financiero. Disponible en: goo.gl/yJgomt.
} 
Se ha dicho de esta disciplina que constituye una verdadera manifestación cultural, la que surge durante el siglo XIX como una reacción frente a los abusos del sistema de producción capitalista industrial (Palomeque y Álvarez, 2000: 63). De hecho, si se observan los albores de la legislación social se aprecia que la pretensión fue tutelar, con la mayor premura, a un proletariado que se encontraba en condiciones materiales deplorables. Más que rigor conceptual o científico, el criterio fue pragmático, buscando asistir con urgencia a una desmejorada clase trabajadora (Garmendia, 2016: 35 y ss). Ejemplo de ello son, en nuestro país, la ley de habitaciones obreras de 1906 y la ley de la silla de 1914.

Con su evolución, la doctrina del Derecho del Trabajo fue construyendo su propia estructura dogmática. Así, apareció la subordinación o dependencia, cuyo aporte es atribuido a Barassi y la cual vino a consolidar una fórmula útil para distinguir las relaciones laborales de aquellas propias del derecho común (Ugarte, 2007: 35). Con ella se puede hablar ya de una figura identificable, cuyos contornos se delinean como los de un tipo de trabajo humano, libre, productivo, por cuenta ajena y dependiente (Alonso Olea, 1994: 38). Cabe destacar, por otro lado, que este desarrollo teórico, sin desmedro al afán científico que lo ha guiado, siempre ha conservado la inspiración moral y antropocéntrica que incidiera en el nacimiento de la disciplina (Gamonal y Guidi, 2015: 13), por lo que no cabe duda que el Derecho del Trabajo, a pesar de su evolución, nunca ha perdido su espíritu tutelar.

El mismo Barassi precisó el concepto de subordinación como una sujeción «plena y exclusiva» del trabajador al poder «directivo y de control» del empleador (Ermida y Hernández, 2002: 272). No es, por cierto, una sujeción similar a la de las obligaciones que nacen de cualquier contrato, sino que se trata de una subordinación de tipo personal, en que el trabajador se coloca él mismo a disposición del poder directivo del empleador. De este modo, a diferencia de una típica convención civil o mercantil, en el contrato de trabajo las partes asumen y aceptan una posición jerárquica. En España, a título de ejemplo, el Estatuto de los Trabajadores señala que la subordinación está presente cuando los servicios se prestan dentro del ámbito de organización y dirección de otro ${ }^{3}$. En Gran Bretaña, el énfasis se encuentra en el poder de mando o poder de control del empleador sobre el trabajador (Gamonal y Guidi, 2015: 47). Es el empleador, en definitiva, quien detenta la potestad de determinar qué, cómo, dónde y cuándo realizar el trabajo (Galiana, 1978: 32).

Al categorizar el concepto, se dice que la subordinación puede ser de tipo económica, vale decir, determinada por la dependencia del operario respecto de la retribución que obtiene de parte del empleador; técnica, por cuanto el trabajador se encuentra en la obligación de seguir las instrucciones del empresario; jurídica, ya que, dada la estructura jerarquizada de la empresa, el empleado debe someterse a las órdenes del empleador o; moral, en el sentido que el trabajador debe respeto al empresario (Thayer y Novoa, 2016: 38). También se habla de una noción física y otra funcional de la subordinación, vinculando la primera con rasgos materiales de la relación, como los recientemente descritos, mientras la segunda coloca el énfasis en el control del proceso productivo (Ugarte, 2007: 54 y ss.).

Es posible considerar como elementos constitutivos de la subordinación tanto a la dependencia personal como a la inserción del trabajador en la estructura de la empresa (Gamonal y Guidi, 2015: 48). Por lo mismo, se encuentra muy ligado con el concepto de ajenidad, que se comprende como la cesión por parte del trabajador a otro de los resultados o frutos de su

\footnotetext{
${ }^{3}$ Real Decreto Legislativo 2/2015, Art. 8.
} 
esfuerzo. Ambos términos, la subordinación y la ajenidad, se vinculan estrechamente: son como «dos caras de la misma moneda» (Ermida y Hernández, 2000: 286). Mientras aquella coloca el foco en la ejecución del trabajo, esta se centra en el destino y los resultados del mismo (Irureta, 2007: 8).

También se concibe a la subordinación como un término aproximado para cuya aplicación es necesario realizar un juicio de semejanza con cada caso concreto por medio de la utilización de un sistema de indicios abiertos y elásticos (Ugarte, 2008: 5). Según esta concepción, la subordinación opera en realidad más como un tipo que como un concepto. Tales indicios, según la jurisprudencia nacional, son elementos demostrativos o manifestaciones concretas que deben verificarse en cada situación particular (Rojas, 2015: 15). Se cuentan entre ellos, por ejemplo, la obligación de asistencia, el cumplimiento de horario, la subordinación a instrucciones y órdenes, la continuidad en la prestación de servicios, la existencia de fiscalización superior, concurrencia al lugar de trabajo, el deber de informar la labor realizada, la exclusividad en los servicios, etc.

La subordinación, si bien no es perfecta para todos los casos que se presentan en el cotidiano, se ha revelado como una herramienta idónea y capaz de satisfacer tanto las necesidades ontológicas y axiológicas del Derecho del Trabajo, así como también los requerimientos metodológicos que exigen un criterio más o menos claro a la hora de delimitar los contornos del sujeto protegido. Se trata, por lo mismo, de un instrumento útil para la resolución de los conflictos que se presentan en la práctica y que también cubre razonablemente las distintas hipótesis entre las posibilidades existentes. Por ello, se le califica como una herramienta eficiente y eficaz (Ugarte, 2008: 7 y ss).

En Chile, si bien la doctrina y la jurisprudencia desde temprano utilizaron a la subordinación o dependencia como elemento central en la aplicación de las reglas laborales, el legislador recién la incorporó formalmente en el Decreto Ley $N^{\circ} 2.200$ de 1978 (Ugarte, 2008: $51)$.

Hasta la fecha, en general, la subordinación mantiene su rol preponderante en el Derecho del Trabajo y uno casi exclusivo en el caso de nuestro país. Sin embargo, durante las últimas décadas, a raíz de la definitiva desaparición del modelo fordista/taylorista y de las formas clásicas de empleo se ha puesto en entredicho que continúe siendo la mejor fórmula.

\section{2.- La subordinación en crisis, deslaboralización y zonas grises}

Como se dijo, desde hace ya un tiempo la subordinación viene siendo puesta en tela de juicio como «la» herramienta central del Derecho del Trabajo. Parte de la crítica se sostiene en que se trata de un concepto que pone el acento en un elemento formal (el sujeto objeto de la dirección y mando del empleador) en circunstancias que lo deseado por el Derecho del Trabajo sería paliar un problema de tipo social (tutelar al sujeto que necesita de protección debido a su situación económica desmedrada que lo coloca bajo riesgo de ser explotado). Esta dicotomía se advierte, por ejemplo, en que trabajadores socialmente necesitados de protección carecen, sin embargo, del elemento formal de subordinación que permita al Derecho del Trabajo brindárselas. Por el contrario, es común encontrar a quienes cuentan con toda la protección del ordenamiento laboral pero que, paradojalmente, si se atiende a su capacidad económica y/o a su poder de negociación, no parecen necesitarla. Es lo que se ha denominado como «el estrabismo del Derecho del Trabajo» (Ugarte, 2008: 55). 
Por otro lado, en algún momento del Siglo XX, la empresa inició una búsqueda de mayor flexibilidad en la producción, gestión y comercialización de sus productos, lo que desembocaría en la llamada «crisis flexibilizadora o crisis de segregación» (Galiana, 1998. 47 y sgtes.). Hoy su afán es ser más ligera, simple y eficiente, por lo que ha decidido no intervenir directamente en todas las etapas del proceso productivo, sino que opta por desplazar algunas actividades (Cruz, 2000: 253).

Bastante se ha escrito sobre la extinción de la fábrica, la preponderancia del trabajo intelectual e inmaterial, la descentralización productiva, la aparición y uso de nuevas tecnologías y la globalización como parte de los factores desencadenantes de nuevas formas de trabajo, donde ya no parece tan sencillo verificar la concurrencia de la subordinación o dependencia jurídica (Henry, 2012: 2-20).

A causa de lo expuesto, han proliferado modalidades como la subcontratación, la externalización, las empresas proveedoras de trabajadores, la creación de empresas unipersonales, de cooperativas de trabajadores independientes, etc., figuras que, en definitiva, apuntan a deslaboralizar las relaciones de trabajo, ocultando la subordinación o expulsándola del quehacer propio de la empresa. Este es, justamente, el fenómeno sistematizado doctrinariamente como «la fuga, huida o emigración del Derecho del Trabajo» (Ermida y Hernández, 2002: 278).

En tal contexto, no es de extrañar que se auspicie por algunos sectores la revalorización del trabajo autónomo. Como grafica Supiot, la empresa pretende así alcanzar la fantasía de una «industria sin fábricas, a la cual la propiedad de los signos (marcas, estándares, patentes, etc.) eximiría de la molestia de tener que fabricar cosas y emplear hombres» (Supiot, 2007: 180 y ss). Por ello, el empresariado atribuye a la autonomía la supuesta virtud de constituir un factor de innovación que exacerba la capacidad de cada trabajador, a la vez que le permite una mayor flexibilidad personal en cuanto a horarios, lugar de desempeño, tipos de servicios, etc. Pero, como advierte el mismo autor, en realidad este fomento apunta, en parte y en casos, al intento de expulsar a los trabajadores de la protección que brinda el ordenamiento jurídico laboral, incluso, a los menos calificados y a quienes se encuentran en las situaciones más precarias (Supiot, 1998: 11). Por lo mismo, concluye por catalogar al trabajo independiente como una estrategia fraudulenta para desregular protecciones al trabajador. Opino que tal temor no es injustificado. Una manifestación de ello se encuentra en el caso de los así llamados «falsos autónomos», esto es, aquellos prestadores de servicio que son tratados como independientes pero que, jurídicamente, se encuentran dentro de la categoría de los trabajadores subordinados (Caamaño, 2004: 65). Se trata de un típico evento de simulación laboral relativa, donde se pretende ocultar un contrato de trabajo bajo la apariencia de un convenio regido por el derecho común o civil (Irureta, 2013: 220).

Lamentablemente, clarificar la naturaleza autónoma o subordinada de una prestación de servicios no siempre resulta sencillo. Muchas veces la realidad, la práctica y la evolución superan los más sofisticados márgenes fabricados por la teoría y la dogmática. De allí que se hable de «zonas grises», justamente, para referir aquellos casos en que no existe certeza si se encuentran dentro o fuera de las fronteras del Derecho del Trabajo (Llamosas, 2009: 107).

Durante los últimos decenios ha florecido la discusión sobre las fronteras ya que, como se aprecia, las nuevas formas de producción y organización del empleo colocan al empresariado en la posibilidad cierta de evitar la contratación laboral (Lujan, 2005: 34). Determinar, entonces, dónde están los límites de éste se relaciona directamente con excluir o no los trabajadores de su esfera de protección. Y no solo eso. La demarcación también impacta en la aplicabilidad de una 
serie de instituciones del Derecho Social y del Estado de Bienestar que se vinculan con la figura clásica del trabajador subordinado (Peliza, 2006: 1). Este aspecto, cabe destacarlo, resulta muy patente en nuestro país, donde el vínculo entre el Derecho del Trabajo y la Seguridad Social, por ejemplo, es sumamente estrecho.

\section{3.- Las alternativas a la subordinación}

En el escenario descrito, la discusión doctrinaria ha visto surgir y desarrollarse varias elucubraciones e ideas con la pretensión de substituir o complementar a la subordinación como herramienta definidora de laboralidad. La disyuntiva está abierta sobre si sigue siendo idónea, por sí sola, para definir la existencia de un contrato de trabajo (Henry, 2016: 11).

Se han ofrecido distintas propuestas, como la dependencia económica, la actividad productiva e incluso, la protección de todas las profesiones asalariadas, con distintos grados de tutela (Supiot, 1998: 97). Para efectos del análisis agruparemos tales propuestas en dos modelos fundamentales ${ }^{4}$ : el primero plantea incorporar estas nuevas figuras íntegramente dentro del entramado de protección del Derecho del Trabajo, el segundo; incorporarlas solo de forma parcial.

La primera fórmula propone la total difuminación de los límites entre el trabajo dependiente y el trabajo autónomo, otorgando protección a cualquier modo de prestación de servicios en la que se intercambie salario por actividad (Palomeque, 2000: 27). Se explica, en alguna medida, por los cuestionamientos analizados en el apartado anterior, donde se desliza como un problema la excesiva utilización de la simulación laboral. Tal vez por ello, en determinado momento, el Derecho del Trabajo optó por un criterio expansivo, interpretando con sentido elástico el concepto de subordinación para, así, aplicarlo a la mayoría de los casos posibles. De este modo, se intentó dotar a la disciplina de una fuerza o intensión centrípeda o vis attractiva (Palomo, 2014: 5), bajo cuyo espíritu se ha llegado, incluso, a postular que todas las obligaciones de actividad se concentren bajo el formato de una relación jurídica laboral (Carmelynck y Lyon-Caen, 1974: 18) ${ }^{5}$.

Dentro de esta gama de ideas se encuentran múltiples variables, en que el propósito es configurar un derecho común del trabajo, vinculado al ejercicio de una actividad humana, superando así el concepto de subordinación. De extremarse esta postura, sin embargo, se advierte, además de la falta de claridad conceptual y una consecuencial incerteza jurídica; un peligro de orden más práctico, cuál es que una protección tan amplia en sus posibilidades concluya por diluir la acción tutelar del Derecho del Trabajo.

El modelo de inclusión parcial, por su parte, presenta dos opciones: una que propone un método abierto y otro, uno cerrado. La primera de estas fórmulas se efectúa por medio de una cláusula que, de modo general y abstracto, define a un colectivo protegido, otorgándole algunas de las garantías que, hasta ahora, se utilizan comúnmente para cautelar a los trabajadores subordinados. Es, por ejemplo, el caso de la conocida parasubordinación o trabajo económicamente dependiente, que se refiere a quienes no desarrollan sus funciones bajo estricta subordinación y dependencia pero que, por su menor capacidad económica frente al empresario, prestan una colaboración continua y coordinada con este bajo evidentes condiciones de

\footnotetext{
${ }^{4} \mathrm{Al}$ efecto se sigue la clasificación de José Luis Ugarte, en Ugarte, 2008: 64 y ss.

${ }^{5}$ En el mismo sentido Durand, 1952.
} 
inferioridad (Ermida y Hernández, 2002: 66). Es el caso del TRADE en el sistema español, el parasubordinati en Italia, el worker en Inglaterra y el arbeitnehmerahnliche personem en Alemania, todos quienes ejercen su actividad de forma independiente, pero perciben al menos el 50\% de sus ingresos de parte de un único ordenante (Auvergnon, 2016: 38).

En el caso de España, el Estatuto del Trabajo Autónomo regula la figura del TRADE (trabajadores autónomos económicamente dependientes) precisándoles como aquellos que realizan una actividad económica lucrativa, de forma habitual, personal, directa y predominante para un cliente del que perciben, al menos, el $75 \%$ de sus ingresos ${ }^{6}$. Respecto de esta figura, importante es señalarlo, se han vertido profusas críticas. Autores la han catalogado como fracasada y poco protectora (Todolí, 2015: 20), a la vez que se le acusa de ser una política legislativa indefinida que concluye por generar formatos de protección diferenciados para los trabajadores, lo que crea verdaderas categorías entre ellos (Fernández, 2016: 46). En lo personal, comparto la preocupación por los riesgos descritos pero, a contra punto, considero que la sola posibilidad de la elusión, que es una imperfección muy característica de esta disciplina, no parece razón suficiente para descartarla como herramienta potencialmente útil a la hora de examinar propuestas para enfrentar los desafíos presentes.

La segunda opción, de la inclusión cerrada, se utiliza mediante la estructuración de un régimen específico para un colectivo muy concreto de personas, que se encuentran fuera del ámbito protector configurado por la subordinación, y al cual se define extender todo o parte del Derecho del Trabajo. Es el caso de las relaciones laborales especiales, las que también existen en nuestro sistema y que se establecen en atención a variados criterios, por ejemplo, debido a razones de ausencia o disminución del grado de subordinación. Es la situación del teletrabajo o de los trabajadores exentos de jornada laboral, a quienes el artículo 22 del Código del Trabajo reconoce expresamente como sujetos protegidos por el ordenamiento laboral.

Si se echa un vistazo desde fuera de nuestra disciplina, también es posible encontrar otros estatutos jurídicos que, eventualmente, pueden entregar algún tipo de protección a trabajadores que se encuentren fuera de los términos tradicionalmente determinados por la subordinación. En Francia, por ejemplo, el trabajador autónomo o parasubordinado puede crear una sociedad mercantil, ya sea como una empresa unipersonal de responsabilidad limitada o una sociedad por acciones simplificada unipersonal ${ }^{7}$. En el primer caso el gestor adscribe al régimen social de los independientes. En el segundo, puede incluso gozar del régimen general de la seguridad social en caso de tratarse de un dirigente asimilado-asalariado, en virtud del estatuto de auto-empresarios creado el año 2008 (Auvergnon, 2016: 29-31). En Chile, por su parte, el socio gestor y el empresario individual son incentivados por la normativa tributaria para enterar aportes previsionales voluntarios por medio de la figura del sueldo empresarial ${ }^{8}$. Esta fórmula, sin embargo, presenta el riesgo de ser utilizada para simular contratos comerciales donde, en realidad, hay figuras laborales, lo que finalmente significa restar protección al operario. Así ha sucedido en nuestro país, por ejemplo, con situaciones como el publicitado caso de los rostros de

\footnotetext{
${ }^{6}$ Ley 20/2007, artículos 1.2 d) y 11.

${ }^{7}$ Figuras que también se replican en Chile en formatos similares a través de las EIRL y SPA, respectivamente.

${ }^{8}$ En efecto, el inciso tercero del $\mathrm{N}^{\mathrm{o}} 6$ del artículo 31 de la Ley sobre Impuesto a la Renta, a la luz de las instrucciones del Servicio de Impuestos Internos, especialmente la Circular $\mathrm{N}^{\circ} 42$ de 1990, permite como gasto necesario para producir renta el sueldo empresarial siempre que el socio gestor o empresario individual, además de trabajar efectivamente en el negocio o empresa, cotice efectivamente hasta el máximo imponible en el sistema previsional.
} 
televisión ${ }^{9}$, que ha sido declarado y sancionado tanto por la Dirección del Trabajo como por los tribunales de justicia ${ }^{10}$. Y Uber, por cierto, no se encuentra ajeno a esta realidad. En efecto, recientemente en España el Juzgado de lo Social $N^{0} 9$ de Barcelona declaró que un director de marketing contratado como empresa para desarrollar sus actividades escondía, tras esa figura, una verdadera relación laboral encubierta puesto que, en los hechos, concurría diariamente a su trabajo, cumplía horario y debía sujetarse a las directrices entregadas por la compañía ${ }^{11}$.

El mismo modelo francés considera sistemas híbridos que mezclan actividad independiente y empleo asalariado: se trata de las figuras del contrato indefinido interino y el «porte salarial», que son tipos de servicios prestados en régimen de tercerización. El primero se refiere al acuerdo concluido entre un trabajador y una empresa de trabajo temporal para la ejecución de misiones sucesivas en favor de una usuaria, donde se consideran períodos de misión e intermisión, durante los cuales se le garantiza una remuneración al empleado. El «porte salarial», a su vez, trata de una especie de suministro en que el trabajador cuenta con conocimientos especializados y que le permiten, a él mismo, buscar sus clientes y concertar con ellos una retribución. En estos casos, si bien el régimen de subordinación entre el trabajador y la empresa que lo pone a disposición es prácticamente ficticio, el empleado está en situación de acceder al régimen de seguridad social (Auvergnon, 2016: 31-32). Estas fórmulas, en principio extra laborales, pueden sin embargo adaptarse y de hecho, el criterio híbrido que las caracteriza es posible compatibilizarlas con figuras como el contrato fijo discontinuo o el contrato fijo periódico del ordenamiento español ${ }^{12}$; o incluso en nuestro país, con el contrato part time; casos en los cuales se crea el espacio para complementar la tutela del ordenamiento laboral con la actividad autónoma del mismo trabajador.

\section{3.- La economía colaborativa y el caso Uber}

\section{1.- Sharing economy y Uber economy. Su impacto en el mundo del trabajo}

Se dice que estamos en presencia de una industria 4.0, o de la $4^{\text {a }}$ Revolución Industrial. Así lo mencionan, por ejemplo, análisis del World Economic Forum, informes de la OCDE sobre economía digital o documentos de la Comisión y el Parlamento europeos (Aragón, 2016: 13). El Comité Económico y Social Europeo, concretamente, ha aprobado en los últimos años 30 dictámenes vinculados directamente con la economía digital (Goerlich, 2016: 136).

\footnotetext{
${ }^{9}$ Como surgió y se expandió la elusión de impuestos en la industria de la televisión. Ciper Centro de Investigación Periodística. Disponible en goo.gl/DsKjVH.

10 Al efecto: Corte Suprema, sentencia de reemplazo de 16 de Junio de 2011 dictada en causa sobre Recurso de Unificación de Jurisprudencia en causa rol 205-2011 caratulado Soza con Televisión Nacional de Chile, recaída sobre sentencia de 19 de Noviembre de 2010 dictada por la Corte de Apelaciones de Santiago en causa rol 959-2010 sobre de recurso de nulidad interpuesto contra sentencia de 6 de Julio de 2010 dictada por el Segundo Juzgado de Letras del Trabajo en causa Rit T-33-2010; Dirección del Trabajo, Informe de fiscalización a empresa Universidad Católica de Chile - Corporación de Televisión - Canal 13. Disponible en goo.gl/QXZy4U.

${ }^{11}$ Juzgado en lo Social No 9 de Barcelona, sentencia 29/2017. Disponible en goo.gl/MFemLQ.

${ }^{12}$ El Estatuto de los Trabajadores contempla un contrato indefinido para actividades cíclicas pero permanentes, sea que estas se repitan en fechas ciertas o no. El primero es el contrato fijo periódico y el segundo, el fijo discontinuo, y se encuentran regulados en los artículos 15.8 y 12.3 , respectivamente.
} 
Los actuales avances tecnológicos en temas digitales, de comunicaciones, robóticos, informáticos, etc., implican también una sustancial transformación del empleo. Entre muchas manifestaciones de ello, se aprecia que las posibilidades de internet permiten un contacto directo e inmediato entre el consumo y la producción, la que, a su vez, se puede dar de forma completamente automatizada (Goerlich, 2016: 179). Ello ha dado pie al surgimiento de la denominada economía colaborativa o sharing economy.

En Europa, estudios recientes dan cuenta que un 52\% de los consumidores conocen los servicios ofertados por la economía colaborativa (Parlamento Europeo, 2016), que trata de un método para compartir, intercambiar, prestar, alquilar y regalar bienes y servicios, el cual utiliza plataformas electrónicas para acercar a los interesados en participar de alguna transacción (Comité Económico y Social Europeo, 2014). Se plantea que sus rasgos definitorios son el uso de internet; la interconexión en red de personas y/o activos; el acceso al uso de productos (tangibles o intangibles) y; el cariz de confianza en las transacciones (Alonso, 2016: 4). Quienes operan como prestadores de este modelo son particulares que ofrecen un servicio más bien de modo ocasional (Comisión Europea, 2016: 5). Su esencia se encuentra en la colaboración más que en el lucro o ánimo de desarrollar negocios, y ejemplos claro de este modelo son aplicaciones como BlaBlaCar, que permite compartir automóvil y gastos en desplazamientos, y NeighbourGoods, que facilita el préstamo de artefactos domésticos (Ginés y Gálvez, 2016: 4 y ss.).

El modelo Uber economy se asocia a estos nuevos formatos y formas de empleo. Se trata de un trabajo sobre demanda a través de aplicaciones - works on demand via apps - en que prestador y usuario se conectan on-line, pero donde el servicio se presta off-line (De Stefano, 2016). Para contextualizar el fenómeno, es necesario precisar conceptos como on-demand economy y crowdsourcing.

Se habla de on-demand economy para referir actividades económicas basadas en la utilización de plataformas electrónicas que permiten el matching inmediato entre el usuario que solicita un bien o un servicio y el sujeto que puede facilitárselo (Dagnino, 2015: 4). El Crowdsourcing, por su parte, se caracteriza por la descentralización de un servicio mediante un llamamiento dirigido a un gran número de personas en forma de convocatoria. Este proceso resulta posible gracias a las nuevas tecnologías que permiten, por ejemplo, la sustitución de trabajadores por una open call.

Uber declara ser un caso representativo de sharing economy. Sin embargo, muchos no comparten esa premisa, dentro de quienes me incluyo. Ello porque el objetivo de Uber no es solo servir de puente para una actividad de colaboración entre conductores y clientes, sino que se trata, más bien, de una organización con claro afán empresarial, el que se desarrolla en base a un modelo on-demand economy, funcionando operativamente mediante el crowdsourcing para prestar así, finalmente, un verdadero servicio de transporte de pasajeros. La doctrina norteamericana, por cierto, ha calificado este método como un tipo de crodwork offline específico (Todolí, 2015: 3).

La clave de Uber reside en la subdivisión del trabajo así como en disponer de un gran número de operarios autónomos prestadores del servicio para, de este modo, garantizar una oferta suficiente que cubra la demanda (Ginés y Gálvez, 2016: 6).

Según se dice, la economía colaborativa generaría entre 25 y 30 mil millones de dólares norteamericanos de rentas anuales, las que se doblarían cada 18 meses (Auvergnon, 2016: 27). Se 
indica también que crea nuevas oportunidades para consumidores y emprendedores, por lo que se estima puede contribuir de manera significativa al empleo, la competitividad y el crecimiento ${ }^{13}$.

Sin embargo, un reciente estudio al alero de la Europa Trade Union Institut señala que los impactos de esta revolución digital en el campo del empleo implican riesgos de pérdida masiva de puestos de trabajo, desregulación de mercados, desfinanciamiento de la seguridad social y erosión de la base impositiva (Degryse, 2016: 23). En el caso concreto de Uber y otras plataformas similares, se estima que los operarios serán personas modestas, que compartirán la suerte de oficios menores y eventuales como cuidadores de mascotas o plomeros (Raso, 2016 a: $8)$.

Desde la perspectiva regulatoria, este nuevo tipo de realidad genera incertidumbre en variados aspectos. En primer lugar, surge la duda sobre la aplicabilidad de las normas vigentes o si es necesario modificar éstas, análisis que inevitablemente deja espacio para un período intermedio sin claridad, cual parece ser aquel en que nos encontramos ahora (Doménech, 2015: 70).

En cuanto respecta al Derecho del Trabajo, la economía colaborativa formula problemas a los marcos jurídicos existentes, ya que replantea los límites entre trabajo por cuenta ajena, por cuenta propia, prestación profesional, trabajo subordinado, etc (Comisión Europea, 2016: 2). De este modo, el efecto disruptivo de este nuevo modelo coloca una interrogante sobre los mecanismos utilizados tradicionalmente por la disciplina $\mathrm{y}$, especialmente, sobre su utilidad para cumplir con sus fines. Concretamente, modifica de manera sustancial la naturaleza del empleo toda vez que instituciones como la jornada de trabajo, el salario mínimo y la seguridad social se basan en la figura típica del trabajador sujeto a las directrices estrictas del empleador. Por lo mismo, al modificarse los contornos del sujeto objeto de protección por parte del Derecho del Trabajo surge la preocupación de que un considerable número de empleados se vean excluidos o privados de los derechos laborales y sociales.

Es especialmente claro el aumento de la actividad por cuenta propia en los sectores de servicios vinculados a las nuevas tecnologías informáticas y computacionales, particularmente por medio de la práctica del crowdsourcing (Doz, 2016: 140). Estudios recientes dan cuenta que en Estados Unidos, de un universo de 8000 trabajadores autónomos ya el 15\% de ellos utiliza las plataformas on line. Del mismo universo, un $14 \%$ preferiría contar con un trabajo típico y un 16\% debe realizar varias actividades para subsistir (Evanz y Byhovskaya, 2016: 109).

\section{2.- El trabajo al interior de Uber}

Uber se presenta como una simple plataforma tecnológica que solo pretende poner en contacto a conductores con pasajeros. Así, este software actuaría como una herramienta de intermediación, servicio por el cuál cobra una suma de dinero tanto a clientes como a choferes. Uber niega que proporcione alguna clase de servicio a los pasajeros, así como también desconoce su calidad de transportista. De este modo, se declara un modelo de negocios que no utiliza la figura de la subordinación o dependencia jurídica respecto de operario alguno, con lo que se sitúa en el exterior a las fronteras del Derecho del Trabajo.

\footnotetext{
${ }^{13}$ Comunicación de la Comisión al Parlamento Europeo, al Consejo, al Comité Económico y Social Europeo y al Comité de las Regiones. Una agenda europea para la economía colaborativa \{SWD (2016) 184 final\}
} 
Concretamente los conductores, a quienes Uber denomina como sus socios, se contactan por medio de su página web ${ }^{14}$. La empresa los selecciona, para cuyo efecto evalúa sus antecedentes y exige que posean un nivel de formación, pericia y experiencia adecuados para prestar servicios de transporte en forma profesional, requisitos que deben mantener durante la vigencia de la relación. Posterior a esta selección, les entrega una capacitación para el uso del software o aplicación en el teléfono inteligente.

Mediante la aplicación, los clientes envían una solicitud de servicio de transporte a Uber, que la asigna al conductor más cercano, el que puede aceptar o rechazar esa petición. En caso de verificarse la operación, el cliente paga los servicios efectuados con tarjeta de crédito, recibiendo el conductor su pago semanalmente por medio de depósitos electrónicos. Dichos pagos se determinan en función del número de viajes efectuados por cada conductor, descontado el porcentaje fijado por Uber. Desde hace un tiempo, los pasajeros también pueden cancelar en efectivo, en cuyo caso, la empresa descuenta su porcentaje desde el fondo formado con todos los pagos efectuados con tarjeta de crédito al mismo conductor. Las tarifas por cada servicio son determinadas unilateralmente por Uber y, asimismo, la empresa se reserva la facultad de modificarlas, por ejemplo, para ofrecer promociones a los usuarios.

El conductor puede aceptar o no las solicitudes de trabajo, pero si se encuentra activo y rechaza las llamadas consistentemente es muy probable que sea desconectado. Por otro lado, la empresa se encarga directamente de incentivar a los conductores para que no se desconecten.

Uber no cuenta con vehículos propios: los automóviles son de dominio de los mismos conductores y ese es, precisamente, uno de los requisitos para ser reclutado por la empresa. Sin embargo, Uber mantiene un estatuto con derechos y obligaciones, el cual debe ser aceptado por cada conductor previo a operar la plataforma. Dicho catálogo establece las condiciones en que deben prestarse los servicios.

Para tener acceso a operar con la aplicación, el socio conductor debe previamente aceptar un documento en que se explicitan las condiciones de la relación ${ }^{15}$. Se trata a todas luces de un contrato de adhesión cuyos términos no pueden ser discutidos ni siquiera mínimamente. Allí el mismo conductor declara expresamente reconocer su condición de autónomo; así como que la única relación que lo une con Uber es la prestación del servicio tecnológico que esta le presta.

Si se observa detenidamente la situación de cada conductor de Uber es posible advertir tantas formas de trabajo distintas como personas hay ejecutándolo. Cada operario presta sus servicios según intereses y necesidades propias. Así, en los extremos, se encuentra por un lado a quienes adoptan este trabajo como su fuente principal acaso única de ingresos, los que seguramente están conectados la mayor parte de su tiempo con la aplicación y aceptan todos los viajes que les sea posible realizar. Ellos, probablemente, se preocupan de cumplir puntillosamente con las recomendaciones impartidas por la empresa ya que, finalmente, su economía depende de eso. En casos como éste se observa con bastante nitidez una situación de subordinación y dependencia.

Distinto es el caso de quienes, por ejemplo, adoptan su membresía con el propósito de complementar ingresos. Ellos se conectarán en los horarios que les acomoden, los que probablemente no serán uniformes ni continuos. Se trata de conductores que, seguramente, cuentan con otras rentas, por lo que no dependen económicamente de su afiliación a Uber. Por lo

\footnotetext{
${ }^{14}$ https://www.uber.com.

${ }^{15}$ Disponible en: goo.gl/sT5Tkn.
} 
mismo, se encuentran en condiciones de ser menos aprensivos a la hora de observar las recomendaciones de la empresa $\mathrm{y}$, a su respecto, la relación con esta no se presenta tan subordinada.

Estudios realizados refieren que el trabajo para plataformas como Uber no es, necesariamente, la principal fuente de ingresos para sus conductores. Estadísticamente, se estima que el promedio obtiene aproximadamente un 33\% de sus ingresos de los servicios prestados por este medio, porcentaje que crece a medida que se desciende en el estrato de ingresos económicos de cada trabajador (Evans y Byhovskaya, 2016: 113). Según datos de la OCDE la media de ingresos anuales de los trabajadores atípicos ronda la mitad de lo obtenido por los trabajadores tradicionales ${ }^{16}$.

Con todo y como se aprecia, la subsunción de un determinado tipo de prestación de servicio dentro de los límites del concepto de subordinación muchas veces se torna difusa y ese es, claramente, el caso de los conductores de Uber. Por lo mismo, se debe ubicar este tipo de modelo dentro de las denominadas zonas grises o fronteras del Derecho del Trabajo (Palomo, 2014: 7), lo que exige aclararlas. O al menos, buscar fórmulas para iluminarlas.

\section{4.- El encuentro del Derecho del Trabajo y la Uber economy}

\section{1.- Uber y la subordinación o dependencia jurídica}

El Derecho del Trabajo es una disciplina en constante evolución que debe adaptarse a los cambios sociales, culturales y económicos que se suceden en el quehacer humano. No es novedad para el laboralismo enfrentarse con la necesidad de abordar nuevas formas de empleo generadas, por ejemplo, a raíz de los cambios tecnológicos.

Se considera que la irrupción de los empleos desarrollados por el modelo Uber exige definición y, en concreto, intervención legislativa. Es la línea de lo planteado por la Agenda Europea para la economía colaborativa y por la OIT en su Iniciativa del centenario relativa al futuro del trabajo (Goerlich, 2016, 187). Concretamente sus dictámenes -Agenda Digital (2010), Estrategia para un Mercado único Digital (2015), Agenda Europea para la Economía Colaborativa (2016), entre otros- critican la ausencia de un enfoque global sobre el tema. Se hace allí también una importante distinción entre las actividades efectivamente colaborativas, en que no media el lucro, y aquellas otras que buscan una fuente de beneficios monetarios por medio de la explotación de información reunida a través de las plataformas digitales. Para este último caso es que el Comité Económico y Social Europeo exige se garanticen los derechos fundamentales y la sostenibilidad de los sistemas de protección social (Doz, 2016: 136).

Fernández Brignoni plantea que existen tres posibles formas en que el Derecho del Trabajo puede hacer frente a nuevos fenómenos: un cambio de paradigma de la disciplina, un cambio en su estructura y un cambio en su funcionamiento. Inmediatamente descarta las primeras dos opciones por considerarlas regresivas y atentar contra la esencia misma del laboralismo (Fernández, 2016: 44). Esta es, por cierto, una de las premisas que se siguen en este artículo: el Derecho del Trabajo es protector y no puede dejar de serlo. Si lo hace, sencillamente dejará de ser Derecho del Trabajo.

\footnotetext{
${ }^{16}$ «In it together: Why less inequality benefits all». OECD. Disponible en: goo.gl/th5vTZ.
} 
El análisis pasa a ser, entonces, cómo tutelar a quienes requieren amparo en el contexto planteado por estas nuevas formas de empleo. Para ello, toca desmenuzar las herramientas o fórmulas utilizadas por el laboralismo y partir, como parece lógico, por la más tradicional de ellas: la subordinación.

La Comisión Europea sostiene que la presencia de subordinación es una cuestión a determinar en cada caso. Señala que para tal efecto debe verificarse tanto la naturaleza del trabajo realizado como la existencia de una remuneración. Sobre esta última, sin embargo, aclara que no constituye indicio el solo hecho que sea la misma plataforma la que tramita el pago depositado por el usuario para luego entregarlo al prestador. En cuanto a la naturaleza del trabajo, en general, se espera que se trate de una actividad de valor económico de cierta significancia, con lo que excluyen aquellas de pequeña escala o marginales (Comisión Europea, 2016: 13 a 15).

La doctrina especializada se ha dedicado ya a analizar la situación de Uber. Lo mismo ha sucedido con alguna jurisprudencia extranjera. El estudio se ha enfocado, casi exclusivamente, en determinar si el trabajo efectuado por los conductores de esta empresa cabe dentro de los márgenes fijados por la subordinación o dependencia como concepto.

Autores como el uruguayo Juan Raso y el español Adrián Todolí coindicen en que siguen existiendo expresiones de la subordinación tradicional en este tipo de trabajo. Ambos entienden el concepto como la posibilidad de controlar la actividad del trabajador impartiendo directrices sobre la forma en que se deben ejecutar las tareas (Raso, 2016 a: 76), situación que aprecian con claridad en el caso de los conductores de Uber. Coinciden, sin embargo, en que se trata de un nuevo estilo de subordinación, donde las formas clásicas no han desaparecido, pero si se han transformado. Así, por ejemplo, Todolí indica que Uber ha delegado sus evaluaciones en los clientes para asegurar, de este modo, determinados estándares en la prestación de sus servicios (Todolí, 2015: 10). Coinciden también en que, frente a esta nueva forma de organización empresarial, la dependencia debe buscarse especialmente en la integración de los trabajadores dentro de una organización ajena (Raso, 2016 a: 77) ${ }^{17}$.

Es un dato cierto que la subordinación o dependencia jurídica ha venido flexibilizándose desde que se incluye dentro de su órbita de acción ciertas profesiones como la medicina o la abogacía; actividades complejas de ejercer bajo una dirección estricta. Hoy el trabajo subordinado no es incompatible con algún grado de autonomía, incluso bastante amplio, en algunos casos (Ginés y Gálvez, 2016: 13). Por lo mismo, se ha otorgado gran importancia al factor de ajenidad y al desarrollo del trabajo al interior del ámbito de organización de la empresa como elemento diferenciador ${ }^{18}$. Se plantea incluso por algunos autores en el ámbito europeo que el factor ajenidad es el dominante para establecer la laboralidad de un determinado trabajo (Pérez, 2013: 3). Por lo mismo, hoy se habla de una «menor dependencia» como característica principal de estos nuevos modelos de negocios que se configuran con un grado de subordinación atenuado y una mayor libertad a la hora de ejecutar las funciones, pero donde, sin embargo, la empresa mantiene firmemente el control sobre la forma en que se prestan esos servicios (Todolí, 2015: 6).

\footnotetext{
${ }^{17}$ En el mismo sentido, Todolí, 2015: 12.

18 Así, por ejemplo, el Tribunal Constitucional español ha declarado «la existencia de una relación laboral en supuestos de amplia libertad de horario que no desvirtúa la existencia del requisito de dependencia, para lo que no es necesaria la concurrencia de una subordinación absoluta, sino únicamente la inclusión en el ámbito organicista y rector» (STS, 4ª , 29.12.1999). En Ginés y Gálvez, 2016: 13.
} 
Efectivamente, Uber y las demás empresas que desarrollan este modelo de negocios sostienen que sus operarios operan de forma autónoma. Se apoyan en que cuentan con total libertad para determinar su volumen de trabajo, así como su horario. Indican, además, que utilizan medios de producción propios (Ginés y Gálvez, 2016: 13 y ss.). Parte de la doctrina, sin embargo, ha declarado como irrelevante que el trabajador aporte materiales de su peculio a la hora de definir o descartar la presencia de subordinación (Todolí, 2015: 13 y ss.), más en un caso como el de Uber, en que lo realmente costoso es la inversión en tecnología. Al respecto, se argumenta que en modalidades como el trabajo a distancia lo que importa no es el control del modus operandi sino que la vigilancia del resultado. Ginés y Gálvez, en tal sentido, ponen de relieve la total ausencia de una organización empresarial propia por parte de los conductores, descartando así la posibilidad de considerarlos como autónomos (Ginés y Gálvez, 2016: 36 y ss.). Así, cuestionándose si la figura del trabajador subordinado sigue siendo suficiente para amparar a este nuevo tipo de operario, esta doctrina exige que el autónomo, para ser considerado como tal, requiera contar con una estructura propia y con total independencia para definir la forma en que presta sus servicios; sin ceder anticipadamente el fruto de su trabajo y asumiendo, además, el riesgo del negocio (Todolí, 2015: 8-9).

En Estados Unidos The United States Court (Northern District of California), dictaminó que Uber no puede ser considerada solo como una empresa tecnológica sin injerencia en la prestación de los servicios de transporte de pasajeros ${ }^{19}$. Destaca que Uber se encuentra muy involucrada en el mercadeo de sus servicios; en la regulación y monitoreo de las prestaciones; en la calificación y selección de sus conductores, sancionando incluso a los que incumplen sus estándares y; también, en los precios de la compañía. Se coloca el acento en que lo importante no estriba en la intensidad del control que se ejerce por la empresa, sino en el hecho mismo que esta se reserve el derecho de ejercerlo (Fernández, 2016: 48). Igual conclusión adoptó The California Labor Commisions, que condenó a Uber a pagar una importante cantidad a una conductora por considerar que se trataba de una empleada de la compañía y no de una trabajadora autónoma ${ }^{20}$.

Sobre este respecto, es importante destacar que recientemente el Tribunal de Justicia de la Unión Europea (TJUE) resolvió que Uber es una empresa de transporte y no una mera plataforma digital de intermediación entre conductores y usuarios, por lo que no respondería a la calificación de servicio de la sociedad de la información. Si bien este fallo no tiene por objeto final pronunciarse sobre la condición de los conductores, señala entre sus consideraciones que, aunque la empresa no ejerce una subordinación en la forma tradicional, sí efectúa un control indirecto a través de incentivos económicos y la evaluación descentralizada llevada a cabo por los propios pasajeros $^{21}$.

En Londres dos conductores denunciaron a Uber en sede judicial por el incumplimiento de obligaciones laborales como vacaciones y pagos por enfermedad ${ }^{22}$. El 28 de Octubre de 2016, el fallo declaró que se trataba de verdaderos trabajadores y que les corresponden, en consecuencia, todos los derechos que la legislación laboral contempla ${ }^{23}$. Para arribar a tal

\footnotetext{
${ }^{19}$ Caso O’Connor et al. V. Uber Technologies Inc., N C-13-3826 EMC, 11 de Marzo de 2015.

${ }^{20}$ Barbara Ann Berwick v. Uber Technologies Inc., decisión de 3 de Junio de 2015.

21 Tribunal de Justicia de la Unión Europea, sentencia de 20 de Diciembre de 2017, dictada en el asunto C-434/15, Asociación Profesional Élite taxi y Uber System Spain.

${ }^{22}$ Dos conductores denuncian a Uber para que les reconozca vacaciones y baja laboral. El País. Disponible en: goo.gl/8HXBD9.

${ }^{23}$ Employment Tribunal, Case Numbers 2202551/2015 \& Others, de 28 de Octubre de 2016
} 
conclusión, dicha sentencia tuvo especialmente en vista que los conductores ejercen sus funciones bajo una marca que no les es propia y que la publicidad de Uber se refiere a la misma empresa y no al supuesto servicio autónomo de sus socios. Califica además como inverosímil hablar de una simple coordinación entre Uber y sus operadores, cuando en Londres existe una única plataforma y más de treinta mil conductores. Destaca, asimismo, la completa imposibilidad de crecimiento de los operarios, cuya única forma de ganar más dinero es trabajar más horas, sin poder cambiar la forma ni el valor de los servicios que prestan.

Estos fallos, como se aprecia, coinciden con la doctrina comentada en cuanto a que el control del negocio adquiere una connotación significativa a la hora de hablar de subordinación o dependencia jurídica. En tal sentido se argumenta también que, junto con el control sobre la prestación de servicios, los ingresos de esta empresa provienen de cada trabajo realizado, y no del acceso a la base de datos. Además, los clientes no utilizan la aplicación en busca de un catálogo de prestadores, sino que de un servicio concreto (Todolí, 2015: 8).

En latitudes más cercanas, en Brasil, el 33er Juzgado del Trabajo de Belo Horizonte, a inicios de este 2017 se apoyó en el fallo del Reino Unido, que ensalzó en alto grado, para adoptar una decisión bastante similar, acogiendo buena parte de sus argumentos ${ }^{24}$. Esta sentencia también destacó, en un contexto jurídico y económico mucho más cercano al nuestro, como es que las formas de control propias de la subordinación y sus indicios cuentan también con un correlato en este nuevo tipo de trabajo. Es del caso traer a colación que, durante el proceso judicial, una ex gerente de marketing de la empresa aceptó que, en alguna época, los conductores debían comparecer hasta las mismas dependencias de la empresa para recibir un entrenamiento de aproximadamente dos o tres horas, ocasión en que además se les indicaba la forma en que debían comportarse y vestirse. Incluso, indicó que aquellos que recibían una baja calificación por parte de los usuarios eran llamados a rehacer el entrenamiento bajo amenazas de exclusión.

La doctrina, a su vez, también se ha referido a las formas de control propias de este modelo, destacando la interpretación más amplia y flexible que se hace sobre los contornos de la subordinación (Todolí, 2015: 10). Se ha dicho que tal sentido y alcance debe desentrañarse en base al principio protector, el de la primacía de la realidad y complementarlo fuertemente, además, con la dependencia económica (Fernández, 2016: 47).

El fallo británico, que ciertamente ha tenido mucha connotación, también destaca una serie de nuevos indicios aunque acepta que se presentan con ciertas particularidades. Da cuenta, por ejemplo, que si bien es el conductor quien decide cuando trabaja y cuando no, debe sin embargo aceptar un mínimo de viajes y una determinada continuidad de servicios ya que, de lo contrario, se arriesga a ser desactivado de la plataforma. También hace hincapié en que es la misma empresa la que establece la ruta a seguir en cada viaje por medio de su plataforma; la que fija los precios a pagar y la que, también, recibe las quejas de los conductores, imponiendo soluciones que estos se encuentran en la necesidad de aceptar, como el descuento de su retribución en caso que el cliente reclame que se optó por una ruta menos conveniente. En el mismo sentido, la jurisprudencia brasileña, refiriéndose concretamente a la verificación del elemento subordinación, destaca que el cumplimiento de reglas e instrucciones se verifica por medio de las notas y evaluaciones que se encargan a los propios usuarios. Este mismo fallo llama la atención sobre los medios de control directos de Uber, tales como la prohibición de entregar

\footnotetext{
${ }^{24}$ Sentencia de Trigésimo Tercer Juzgado del Trabajo de Belo Horizonte, dictada por el Juez Titular Marcio Toledo Goncalvez recaída en proceso 0011359-34.2016.5.03.0112.
} 
tarjetas de presentación, lo que se considera una falta grave de parte del conductor. Del mismo modo, como dato anexo, cabe destacar que denomina con el apelativo de «uberiana» esta nueva forma de supervigilancia, posible gracias a los nuevos avances tecnológicos, la que califica como más eficaz y represora de lo común por tratarse de un control más difuso.

Este tipo de plataformas solicita a cada conductor entregar información sobre sus características y condiciones personales tales como antecedentes policiales, judiciales, aptitudes sicológicas, verificación domiciliaria, etc. lo que claramente da cuenta de un verdadero proceso de selección laboral (Armas, 2016: 17). Para la ejecución misma del trabajo, se requiere del uso de datos y del rastreo de cada etapa del viaje. De hecho, se cuantifica todo el tiempo que los conductores mantienen activada la aplicación (Evans y Byhovskaya, 2016: 112).

Ahora, como contrapunto a esta línea de opinión y, aun cuando se acepte que efectivamente existen nuevas formas de dependencia o subordinación en la economía virtual, tampoco se puede desconocer que, en el caso de los conductores de Uber, nos encontramos frente a trabajadores que, si bien se integran en una organización ajena, conservan sin embargo importantes rasgos de autonomía. Tal es así que aún Ginés y Gálvez, quienes califican como «evidentemente laboral» la relación existente entre Uber y sus conductores, reconocen en esta actividad un debilitamiento de las formas clásicas de trabajo. Con todo, aceptan que las reglas jurídicas actuales no ofrecen respuestas claras y ciertas ante el fenómeno (Ginés y Gálvez, 2016: 9).

Si la «uberización» de la economía y el fenómeno del trabajo por medio de plataformas es objeto de estudio y análisis en los más variados sistemas es, precisamente, porque se trata de un caso que no encaja del todo en los viejos moldes del Derecho del Trabajo y, especialmente, dentro los márgenes del concepto de dependencia jurídica. La subordinación, finalmente, es una categoría jurídica, esto es, una sistematización de la realidad que el Derecho regula a través de normas y, en el caso de Uber, la subsunción de los antecedentes fácticos en la regla puede resultar sino un poco forzada, al menos dudosa. En este punto, Raso se separa de Todolí y de Ginés y Gálves, quienes en definitiva concluyen que los nuevos emprendimientos virtuales encubren verdaderos vínculos de trabajo subordinado susceptibles, entonces, de ser regulados por el Derecho Laboral clásico. El autor uruguayo, en cambio, en una visión que comparto, plantea que es ineludible aceptar que estamos frente a una realidad de trabajo atípico «que se resiste a ser incorporado a las categorías tradicionales» (Raso, 2016 a: 41 y ss.).

En Chile, desde temprano se utilizó a la subordinación jurídica como el elemento central de la protección laboral aun cuando la normativa no entregue una definición concreta del término ${ }^{25}$. Nuestros tribunales han vinculado el concepto con la manifestación del poder de dirección del empleador, que es quien tiene la facultad de organizar el trabajo y a quien el operario debe, en consecuencia, respeto y obediencia ante sus instrucciones sobre el desarrollo de su cometido ${ }^{26}$.

\footnotetext{
${ }^{25}$ En efecto, la Corte Suprema ha reconocido que «el concepto de subordinación o dependencia no ha sido definido por la ley y su significación se ha circunscrito casi exclusivamente a una de naturaleza jurídica entre empleador y trabajador, aun cuando en esos términos no sólo es propia de una relación laboral, sino también de otras formas de vinculación, por lo tanto, se dificulta su caracterización para estos efectos. Sin embargo, en este aspecto de la relación laboral, se alude al poder de mando del empleador, reflejado principalmente en dos aspectos: la facultad de impartir instrucciones al trabajador y la prerrogativa de organizar y dirigir las labores». Corte Suprema, sentencia de 30 de marzo de 2010 dictada en causa sobre casación en el fono, rol 9216-2009.

${ }^{26}$ Corte Suprema; sentencia dictada el 30 de Septiembre de 2011 en recurso de casación en el fondo, rol 259-2011.
} 
En nuestro ordenamiento, a diferencia de lo que ocurre en países como Italia, Alemania o el Reino Unido, no existe un estatuto especial para el trabajo autónomo y parasubordinado, donde se aprecia un nivel de protección ajustado o intermedio respecto de quienes lo ejercen. En Chile, o se está dentro de los términos de la subordinación, o no se cuenta con protección alguna por parte del Derecho del Trabajo.

Son varios los casos ubicados en las zonas grises en los que ha existido pronunciamiento judicial de nuestros tribunales. Se trata precisamente de situaciones en que se discute la condición de autónomos o de subordinados de los prestadores de servicio. Ejemplos comunes son, entre otros, el de profesionales médicos o dentales que atienden en clínicas privadas, el de los peluqueros que celebran un contrato de arriendo de sillón y recaudación con alguna empresa y el de los empaquetadores de supermercado. De esas resoluciones judiciales lo único claro es que no existe una respuesta uniforme aunque, cabe destacarlo, es posible apreciar cierta corriente jurisprudencial dispuesta a romper los moldes tradicionales de la subordinación, extendiéndolos a situaciones en que antes no se reconocía la presencia de una relación laboral ${ }^{27}$.

Actualmente se tramita en el Congreso Nacional un proyecto de ley que pretende regular de modo integral la actividad de este nuevo formato de negocios, el que se encuentra en primer trámite constitucional en la Cámara de Diputados ${ }^{28}$. Dicho proyecto no contempló en su origen ninguna forma de protección laboral para los operarios si bien, cabe consignarlo, durante la discusión al interior de la Comisión de Obras Públicas, Transportes y Telecomunicaciones de la Cámara de Diputados se presentó una moción proponiendo una presunción de laboralidad simplemente legal en favor de los conductores, la que aún no se ha resuelto ${ }^{29}$.

Con ocasión del señalado proyecto de ley, la Comisión de Transporte y Telecomunicaciones del Senado de Chile formuló una consulta a la Dirección del Trabajo a fines de 2016. Ante ello, el órgano administrativo emitió un Ordinario refiriéndose a la situación en que se encuentran los conductores de Uber $^{30}$.

Para elaborar dicho Ordinario, la Dirección del Trabajo realizó una inspección a la empresa Uber Spa, administradora en Chile de Uber Technologies Inc. Los resultados de este trabajo dan cuenta de la presencia de más de un indicio de laboralidad tanto en la estructura organizativa del negocio, como en la forma concreta en que los conductores prestan sus servicios. Sin embargo, la conclusión del órgano administrativo fue entregar la decisión final del problema

\footnotetext{
${ }^{27}$ A modo de ejemplo: Corte Suprema en sentencia de 16 de marzo de 2012 sobre Casación en el Fondo pronunciada en causa rol 3480-2011, resolvió que una profesora de inglés no prestaba sus servicios bajo subordinación y dependencia y; en sentencia de 2 de Enero de 2011 sobre casación en el fondo en autos rol 7652-2010 consideró que el contrato celebrado por un médico no configuraba una voluntad tendiente a formar una relación de tipo laboral. Por su parte, la Corte De Apelaciones De Santiago en sentencia de 6 de marzo de 2015 sobre recurso de nulidad en causa rol 1313-2014 negó la calidad de trabajadores a empaquetadores de supermercado. En tanto que el Juzgado de Letras del Trabajo de Valparaíso, sentencia dictada el 14 de Diciembre de 2010 en causa rit M 1146-2010, resolvió que la función de empaquetador que cumplía el demandante era un vínculo de subordinación y dependencia, misma opinión que recientemente tuvo el Juzgado de Letras del Trabajo de la Serena en sentencia de 4 de Septiembre de 2017 dictada en causal rit O 217-2017.

28 Boletín 10937-2015, Proyecto de ley que moderniza la legislación sobre transporte remunerado de pasajeros, iniciado por Mensaje Presidencial No 181-364 de 6 de Octubre de 2016.

${ }^{29}$ Indicación de 8 de agosto de 2017 propuesta por el diputado Giorgio Jackson. Disponible en goo.gl/dDYnwu.

${ }^{30}$ Dirección del Trabajo Ord. 6165, de 29 de Diciembre de 2016.
} 
a los tribunales de justicia, opción que reiteró en un posterior Ordinario emitido con ocasión a la consulta planteada respecto de un caso de responsabilidad por accidente laboral ${ }^{31}$.

En cuanto a nuestros tribunales, en lo que respecta a demandas incoadas directamente en contra de Uber como empleador, hasta el momento se ha dictado solo una sentencia en sede laboral, la que es de fecha anterior al pronunciamiento de la Dirección del Trabajo. Esa resolución rechazó la pretensión del conductor demandante, por considerar que no aportó al proceso antecedentes que dieran cuenta de una efectiva situación de subordinación y dependencia. Ahora, en cuanto a ciertos hechos que sí tuvo por ciertos, los calificó, sin embargo, como indicios insuficientes ${ }^{32}$. Así, por ejemplo, fijó como un hecho del proceso la existencia de una comunidad de choferes que se unen a la empresa como personas naturales o jurídicas con sus vehículos propios, donde esta solo facilita el soporte tecnológico para captar clientes a través de una aplicación. Por su parte, la Corte de Apelaciones de Santiago, recurrida de protección por un conductor de Uber que fuera desconectado de la aplicación, calificó el conflicto como un eventual incumplimiento contractual y, a la desvinculación que se produjo, como la verificación de una condición resolutoria convenida. Valga aclarar, sin embargo, que no se pronunció abiertamente sobre la naturaleza del vínculo ${ }^{33}$.

Como se aprecia a lo largo de este apartado, si bien parece haber una línea doctrinaria y también jurisprudencial que pretende extender los límites del concepto de subordinación hasta hacerlos aplicables a la situación de los conductores de Uber, esta intención no se encuentra consolidada ni en los operadores jurídicos ni tampoco entre los mismos autores. Como botón de muestra, cabe traer a colación nuevamente la sentencia dictada por el 33er Juzgado del Trabajo de Belo Horizonte, en Brasil, que declaró la presencia de subordinación en el caso de un conductor que demandó a Uber condenándole, en consecuencia, a pagar todas las prestaciones derivadas de esa relación laboral. Pues bien, recientemente esa sentencia fue anulada ${ }^{34}$, lo que refuerza que la discusión se mantiene y que el problema está lejos de encontrarse resuelto.

\section{2.- Las posibilidades para enfrentar el dilema}

En la eventualidad de una disputa judicial en Chile, es probable que la actual indefinición signifique una variedad de sentencias contradictorias, a pesar de tratarse de operarios que realizan las mismas funciones y, lo más peculiar, con la misma empresa, la que a todos ofrece idénticas condiciones. Lo disímil de las decisiones podría provenir, en alguna medida, de la forma en que cada uno de los conductores defina ejecutar su trabajo. En efecto, de la simple conversación directa con algunos de ellos se advierte que, así como hay quienes dedican exclusiva o principalmente su tiempo a Uber, otros lo asumen solo como una actividad complementaria. Unos reciben única o mayoritariamente sus ingresos del trabajo de la plataforma y otros, por el contrario, solo pretenden aumentar residual o temporalmente sus emolumentos regulares. Por lo mismo, hay quienes tienen un verdadero régimen de exclusividad con Uber, y quienes no. Ello

\footnotetext{
${ }^{31}$ Dirección del Trabajo Ord 0559, de 1 de Febrero de 2017.

${ }^{32}$ Segundo Juzgado del Trabajo De Santiago, sentencia definitiva de fecha 14 de julio de 2015 en causa Rit O 13882015 caratulados Thompson con Uber Chile Spa.

${ }^{33}$ Corte de Apelaciones de Santiago, sentencia de 24 de Noviembre de 2016 sobre recurso de protección en causa Rol 109.929-2016.

34 «Uber: problema con sus conductores en Brasil y en Nueva York». Siliconweek. Disponible en: goo.gl/x1dPDz.
} 
incide, por cierto, en que algunos conductores son más proclives que otros a aceptar las directrices que entrega la empresa. Así, en conclusión, se advierte que la presencia de indicios de subordinación y la intensidad con que cada uno de ellos se manifiesta es muy disímil en cada caso, razón por lo que se pronostica una alta variación de decisiones a la hora de determinar si se está o no en presencia de una relación laboral.

La particularidad expuesta en nada ayuda al buscar claridades y certezas en la interpretación de categorías jurídicas como lo es, por cierto, la subordinación. Por lo mismo, en este apartado se analiza la recepción y viabilidad de las otras fórmulas de protección, las que fueran previamente indicadas en la primera parte de este artículo.

En Estado Unidos - nada menos - varios pronunciamientos judiciales dan cuenta de una intención de aplicar la protección que otorga el contrato de trabajo a toda prestación en que sea patente el desequilibrio de poder negociador de las partes, independiente a que se acredite o no la existencia de un vínculo de subordinación (Todolí, 2015: 14). Esta visión, no concretada en reglas formales, parece semejante a la fórmula señalada como el método de incorporación íntegra.

Sobre esta opción específica, podría considerarse como perjudicial para aquellos trabajadores que legítimamente prefieran un diseño autónomo a la hora de prestar sus servicios. Por otra parte y, como ya se indicara, una excesiva extensión de la esfera de protección del Derecho del Trabajo puede aparejar una considerable disminución en la intensidad de la misma (Ugarte, 2008: 65), con lo que finalmente se diluye. Así, se teme que esta medida acarrearía una baja general de los estándares de protección a fin de satisfacer expectativas de un universo demasiado grande y heterogéneo (Davidov, 2017: 3).

En cuanto a la opción de la incorporación parcial abierta, parece una posibilidad válida a la hora de analizar la situación de los operarios de Uber, especialmente si se considera que es factible de utilizar, teóricamente, en algunos ordenamientos jurídicos. Es el caso, como se indicó previamente, de la figura del parasubordinado o TRADE en el sistema español, los parasubordinati en Italia, los workers en Inglaterra y los arbeitnehmerahnliche personem en Alemania.

En el caso chileno esta figura no existe, sin embargo, desde el análisis, no parece una opción completamente descartable. Con los debidos ajustes, puede resultar en una fórmula posible de acomodar a la voluntad de cada trabajador según cual sea el nivel de subordinación o dependencia al que se desee someter respecto de Uber. El punto está, sin embargo, en cuáles serían las herramientas de protección que se entreguen y en cómo crear mecanismos que impidan la utilización indebida de esta figura, como la simulación de verdaderas relaciones laborales.

En doctrina, la aplicabilidad de la parasubordinación al caso de Uber tampoco parece tan clara. Se plantea que no habría asimilación posible ya que, si se acoge la tesis de que Uber es solo una plataforma tecnológica, entonces los clientes son los usuarios y, obviamente, no habrá uno mayoritario. Ahora, si se acepta que Uber es una empresa prestadora del servicio de transportes, entonces, se estaría frente de un verdadero contrato de trabajo (Todolí, 2015: 20).

Para Todolí, quien analiza la situación justamente desde el sistema español, donde existe parasubordinación, la opción legislativa más atractiva es la de la incorporación parcial cerrada, mediante la creación de una relación especial que se adapte a las particularidades del caso. Plantea, con razón, que existen ya otras figuras en que se ha mermado la dependencia como factor delimitante, las cuales se han reconocido como susceptibles de ser protegidas laboralmente, señalando como ejemplo la situación del teletrabajo (Todolí, 2015: 21-22). En 
nuestro país, el mismo criterio puede advertirse en el establecimiento de contratos especiales y, especialmente, en el caso de quienes se encuentran exceptuados de jornada laboral según las reglas del artículo 22 del Código del Trabajo, donde precisamente la razón de la regla distintiva es la ausencia de una fiscalización directa.

Juan Raso argumenta por su parte que, así como cambia el mundo y las formas de producción a partir de las plataformas virtuales, es inevitable que los paradigmas de los trabajadores y de la propia relación laboral también cambien. Plantea entonces que el Derecho del Trabajo debe adaptarse a estas nuevas realidades, sin pretender forzar estas en las categorías clásicas de la disciplina. Ofrece como ejemplo de flexibilidad a imitar lo que ha venido sucediendo con la institución del matrimonio en el Derecho Civil. Hace presente que el Derecho del Trabajo es naturalmente empírico, mucho más que de bibliotecas, por lo que propone la utilización de diversos instrumentos de protección que operen de modo diferenciado frente a realidades disímiles, incluidas las herramientas de la Seguridad Social, priorizando por mantener el criterio esencial que es la necesidad de tutela de los económicamente débiles frente a los fuertes (Raso, 2016 a: 41 y ss.).

Al respecto, es interesante traer a colación una doctrina planteada, justamente, en Inglaterra, sistema que, como se ha visto, ha sido pionero en su jurisprudencia sobre la laboralidad de los conductores de Uber. Allí, cierto sector ha propuesto relevar el carácter funcional de la subordinación pero centrándolo en la figura del empleador. Para arribar a ello, se sugiere dejar de lado el análisis fragmentado de la relación existente entre plataforma y prestador de servicios (el conductor, en el caso de Uber), y reconocer la presencia de relaciones complejas entre múltiples partes que interactúan formando así figuras triangulares (al menos), lo que se aprecia en el caso de Uber, los conductores y los usuarios. De este modo, se desarrolla la idea de un empleador determinado por cinco funciones fundamentales las que, en un contexto complejizado como el actual, determinan su presencia y la de un contrato de trabajo. Esas funciones son: inicio y término de la relación laboral; recepción del trabajo y sus frutos; entrega de labores y su pago; gestión del mercado de la empresa y; gestión o emprendimiento de una actividad económica a cambio de una potencial ganancia. Se trata, como se advierte, de funciones bastante específicas y, por consiguiente, sencillas de pesquisar, lo que en concepto de esta opinión simplificaría la búsqueda de la figura del empleador, más allá de la presencia de otros factores (Prassl and Risak, 2017: 15 y ss.).

En este punto, es importante declarar que el presente análisis sobre las fórmulas con que el Derecho del Trabajo podría enfrentar el fenómeno de Uber se ha referido exclusivamente a las herramientas heterónomas de la disciplina. Ese fue el alcance con que se estructuró este artículo, por lo que conscientemente se dejó fuera del estudio las posibilidades que nacen de las fórmulas que entrega la autonomía colectiva. Sin desmedro de lo anterior, vale decir un par de palabras al respecto.

A priori, da la impresión que los instrumentos de la acción sindical que se conocen hasta ahora no parecen adaptables a este nuevo formato de empleos (Goerlich, 2016: 188). Sin embargo, considerando especialmente las insuficiencias legislativas, el desafío parece necesario. Ya la Comisión Europea, con el afán de que se lleve a cabo un examen más detallado de la legislación de la Unión para reducir la incertidumbre y garantizar, así, una mayor seguridad jurídica en lo referente a las normas aplicables a los modelos de empresa colaborativa, plantea la urgencia de modernizar los sistemas de seguridad social, así como el rol que cabe a los demás actores sociales. Destaca expresamente las posibilidades que ofrece el Derecho Colectivo del 
Trabajo, al punto que insta abiertamente al Parlamento Europeo a proteger y alentar el derecho de los trabajadores de organizarse, emprender acciones colectivas y, derechamente, a negociar convenios colectivos (Parlamento Europeo, 2017). Sus opiniones, además, apuntan a la necesidad de la Unión por crear un Mercado Único Digital que permita superar la fragmentación legislativa de la actualidad y, especialmente, dar sostenibilidad al sistema de protección social. Para ello, justamente, otorga gran relevancia al diálogo social y a la negociación colectiva (Doz, 2016: 131).

En México, los conductores de Uber se organizaron y, tras una larga negociación con la empresa (que contó con participación del propio Estado), se alcanzó un acuerdo para establecer un pago por cada viaje, permisos anuales y reglas sobre las condiciones de los trabajadores en todo el Distrito Federal, dando cuenta de una incipiente organización de tipo gremial ${ }^{35}$. En otras latitudes, en Sudáfrica, el pasado 14 de julio la Comisión de Conciliación, Mediación y Arbitraje de África del Sur (CCMA) concluyó que, de hecho, los conductores de Uber son empleados de la empresa tras más de un año de lucha para unirse al Sindicato de Trabajadores de Transportes (SATAWU), lo que finalmente lograron ${ }^{36}$. En nuestro país se cuenta a la Asociación Gremial de Transporte de Pasajeros (AGRETRAPP), que intenta organizar a los conductores de distintas plataformas con el objeto de conseguir mejores condiciones para ellos ${ }^{37}$. Sin embargo, considerando la opción marcadamente heterónoma adoptada por el legislador nacional a la hora de regular la acción sindical, así como su preferencia por la figura del sindicato de empresa, no parece tarea fácil el desarrollo de la organización colectiva para quienes operan en la economía colaborativa, especialmente cuando, en casos como el de Uber, se niega la existencia de un vínculo laboral y de un empleador.

Finalmente, toca dedicar un par de palabras sobre la posibilidad de dejar a los conductores de Uber fuera de los márgenes del Derecho del Trabajo. Es, por ejemplo, lo que ocurre en Costa Rica, vale decir, en un sistema jurídico y una realidad social similares a la chilena. Allí se discute en sede legislativa la opción de considerarlos derechamente como trabajadores independientes sin sujeción laboral ${ }^{38}$ con lo cual, más allá de compartir o no dicha fórmula, se reconoce al menos que la decisión arroja una certeza que hasta aquí no ofrece nuestro sistema.

Esta opción se enmarca, en nuestro criterio, dentro del contexto de la ya citada «huida del Derecho del Trabajo», apelativo que se asigna a aquella doctrina que promueve limitar e incluso reducir el campo de acción del laboralismo en favor de ampliar el ámbito de la autonomía de la voluntad. De este modo, se pretende fomentar el empleo en el actual contexto económico globalizado y liberalizado, aprovechando de modo eficiente las condiciones que ofrecen los nuevos medios tecnológicos y de información. Buena parte de esta posición se ampara, no sin razón, en las deficiencias técnicas del concepto de subordinación, punto sobre el cual se refiere la primera parte de este análisis. El problema de esta fórmula, sin embargo, estriba en la situación de precariedad social de los conductores se mantiene, salvo que se adopte alguna forma de protección extra laboral en su favor.

\footnotetext{
35 «Los conductores de Uber en México protestan por las tarifas». El País. Disponible en: goo.gl/X9L8JM.

36 «Los conductores de Uber en África del Sur pasan a ser considerados empleador». Economía y Negocios. Disponible en: goo.gl/akTKSh.

37 «Grupo de choferes de Uber y Cabify llaman a desconectarse por seis horas». 24 HORAS. Disponible en: goo.gl/4J1SVd.
} 


\section{5.- Conclusiones}

La gig economy, no solo Uber, están cambiando el mundo, la forma en que vivimos y, por supuesto, el modo en que trabajamos. Ante ello cabe plantearse, primero, si el Derecho del Trabajo resulta aplicable en este nuevo escenario; luego, si se requiere modificarlo en algún sentido para adaptarlo a estas condiciones y; finalmente, de qué forma podrían efectuarse tales ajustes, en caso de estimarse ello necesario.

Intentando arrojar alguna claridad, el presente trabajo ha analizado el tratamiento dado tanto por la doctrina como por la jurisprudencia extranjera al empleo en esta nueva economía disruptiva. Se pretende con ello obtener conclusiones que resulten útiles para esclarecer las encrucijadas que también se presentan en nuestro sistema.

Alguna jurisprudencia extranjera ha dado señales de querer insistir en la senda de flexibilizar el alcance del concepto de subordinación para hacerlo aplicable a este nuevo tipo de trabajo. Sin embargo y, a pesar de algunos fallos emblemáticos, esa fórmula no consigue acallar cierto ruido que genera más de alguna duda. Sin ir más lejos, en nuestro propio país, se ha fallado exactamente en el sentido contrario en el único caso seguido judicialmente contra Uber, el cual, justamente, se apoyó en una visión más bien rígida sobre los alcances de la subordinación.

Por lo expuesto, frente a la pregunta sobre si el Derecho del Trabajo tal como está estructurado hoy, fundado en el concepto de subordinación, entrega o no certeza a la hora de fijar su aplicabilidad a los empleos generados por la gig economy, la respuesta concluye por ser negativa. En el mismo sentido se manifiesta parte de la doctrina analizada, incluso aquella que denuncia que se trata de un caso de simulación laboral, la que igualmente acepta las particularidades del caso y las dificultades de la subsunción del concepto en estas nuevas formas de trabajo.

En cuanto a las posibilidades de una respuesta cierta con miras al futuro, la doctrina tampoco es uniforme en sus propuestas. Si bien, como se ha visto, la subordinación como herramienta central sigue siendo aplicable y, aún más, puede adaptarse a las nuevas formas de empleo, para que ello ocurra sus contornos deben flexibilizarse y ello apareja un riesgo muy claro: de seguir estirándose el concepto, este perderá nitidez y, consecuencialmente, cada vez las certezas serán menos.

Como se expuso en este trabajo, nuestra disciplina cuenta con otras herramientas disponibles para fijar los contornos de su esfera protectora. A dicho respecto se destinó también parte del análisis, con las siguientes conclusiones.

La opción de la incorporación integral no tiene recepción en ningún ordenamiento ni tampoco es acogida por la doctrina. Se le critica que, por intentar ampliar en exceso la tutela del Derecho del Trabajo, concluye por debilitarla. Sin embargo, quizás un modo en que se le pudiera dar cabida a esta opción es, como se propone en nuestro país, mediante el establecimiento de una presunción de subordinación, con la posibilidad de ser desvirtuada por la empresa, o una especie de modificación de la carga probatoria.

La fórmula de la incorporación parcial abierta, factible de uso en sistemas comparados aunque discutida por la doctrina no parece, sin embargo, descartable, ya que ofrece una medida de protección que no se encuentra sujeta a un criterio formal sino que a uno de orden sociológico o económico, como por ejemplo, en el caso de los parasubordinados. Los problemas de este 
método, sin embargo, aparecen en su implementación debido a que abre una puerta a la simulación y a la huida del Derecho del Trabajo.

Los métodos de la incorporación integral y de la incorporación parcial abierta no cuentan con antecedentes en nuestro sistema jurídico laboral. No así el modelo de la incorporación parcial cerrada, que conocemos en la regulación de tipos especiales de trabajo, como el de tiempo parcial o el teletrabajo, caso este último que llama la atención para el análisis ya que, por cierto, allí también se encuentran morigeradas las formas clásicas de subordinación. Consideramos que esta opción es una alternativa válida, sin desmedro a la utilización de fórmulas de protección provenientes de la seguridad social, tal vez adaptadas a las particularidades del caso, o a los incentivos que puedan aportar otras ramas jurídicas para formalizar la situación de los conductores.

Con todo, lo cierto es que este tipo de negocios aprovechan un vacío normativo y la escasez de empleo para desarrollarse. Por lo mismo, el escenario planteado por esta economía, que ha sido denominada como disruptiva, presenta una situación un tanto inevitable: la falta de preparación de los operadores jurídicos (legisladores, jueces, especialistas...).

Puestos en este punto, toca entonces definir sobre la opción de legislar o no sobre los nuevos empleos de la Uber economy y otros negocios similares. No hacerlo constituye una decisión política que tiene una consecuencia importante: el paso libre a la autonomía de la voluntad, lo cual irroga como riesgo que la empresa imponga sus condiciones sin contrapeso alguno y luego, con la industria consolidada y con capacidad de hacer un fuerte lobby, el establecimiento de cualquier regulación resultará aún más difícil. Por otro lado, frente a la potencial judicialización de conflictos entre los actores del negocio se advierte un horizonte de inseguridad jurídica, dada justamente la ausencia de normativa clara así como la variedad de escenarios, argumentos y visiones jurídicas que legítimamente puede adoptar cada órgano.

Para el caso de nuestro país, como se indicó, actualmente se tramita un Proyecto de Ley que moderniza la legislación sobre transporte remunerado de pasajeros, pero entre cuyos objetivos no se cuenta, formalmente, regular la situación laboral de los conductores. Con ello, entonces, se mantiene el escenario actual y continúa rondando el fantasma de la inseguridad jurídica, dependiente de la interpretación que en cada caso efectué el juez sobre los alcances del concepto de subordinación.

Considerando la enorme envergadura que ya tiene este nuevo formato de negocios y que todo parece indicar que recién se encuentra en una etapa inicial de desarrollo, lejos aún de su apogeo, parece importante adoptar una posición ante el fenómeno e, idealmente, hacerla explícita y clara.

Colocados, entonces, en la necesidad de emitir un pronunciamiento sobre la situación en que actualmente se encuentra el ordenamiento nacional, toca en primer término reiterar la conclusión principal de este trabajo, esto es, que no arroja una respuesta cierta y clara frente al fenómeno en cuestión. Hecha esta advertencia, y como parte del análisis que se ofrece, cabe declarar lo que sigue a continuación.

Desde una perspectiva de lege ferenda, y en coherencia a la conclusión principal de este trabajo, a la hora de regular el asunto nos pronunciamos en favor de la utilización del método de la incorporación parcial cerrada que, como se indicó, es promovido por parte de la doctrina. Nos parece la fórmula más apropiada para nuestro sistema tanto por las certezas que arroja como por las posibilidades de adaptarla a las distintas necesidades de protección que se requieran fijar. 
Ahora, desde un enfoque de lege lata, consideramos que la subordinación requiere ser interpretada y aplicada según las particularidades de la vida real más que siguiendo estrictos conceptos, muchos de los cuales se formaron al alero de una estructura empresarial y una forma de trabajo ya superados. En tal entendido, por ser más adaptable, optamos por el método tipológico en desmedro del subsuntivo. De este modo, la respuesta se debiera encontrar desentrañando y analizando los indicios de subordinación que se obtengan en cada caso.

Compartimos con aquella jurisprudencia extranjera y parte de la doctrina que estiman que el trabajo dentro de Uber cuenta con indicios propios y particulares que no necesariamente corresponden a los que usualmente han sido utilizados. Concordamos con la superación del concepto estricto o físico de la subordinación, para encontrarla más vinculada al control y dominio productivo. De ese modo consideramos, por ejemplo, que la calificación efectuada por los usuarios respecto de la forma en que es prestado el servicio por los conductores de Uber constituye en definitiva un modo de supervisión, indirecto si se quiere, por parte de la misma empresa.

En definitiva, entendemos que acreditándose indicios de subordinación, por novedosos que estos sean, se configura una relación de trabajo, con todos los efectos que ello conlleva. Cabe destacar que los mismos tribunales chilenos, resolviendo litigios que, al igual que el trabajo en Uber se ubican en las llamadas «zonas grises», han usado un criterio amplio al ponderar los indicios de laboralidad.

Con todo y, a modo de cerrar este trabajo, nos queda reflexionar que el mundo y la velocidad de su evolución van más rápido que el Derecho Laboral, lo que siempre ha sido así. Pero el laboralismo, desde sus orígenes, ha sabido adaptarse a un trabajo que se complejiza y que busca huir de sus tutelas. Es justamente por ello que Américo Plá caracteriza nuestra disciplina como un «derecho en constante transformación» (Plá, 1979: p.23) por lo que parece natural e incluso saludable que, una vez más, se de a la labor de ajustar sus herramientas.

\section{Referencias}

Alonso Olea, Manuel (1994). Introducción al Derecho del Trabajo. Madrid: Ed. Civitas.

Alonso Sánchez, Rosalía (2016). «Economía colaborativa: un nuevo mercado para la economía social». En XVI Congreso de Investigadores en Economía Social y Cooperativa Economía Social: crecimimiento económico y bienestar. Disponible en goo.gl/rv76nh.

Aragón, Jorge (2016). «Notas sobre ¿Una nueva revolución industrial? Economía digital y trabajo». En ¿Una nueva revolución industrial? Economía digital y trabajo. GS Gaceta Sindical reflexión y debate nueva etapa No 27 DIC 2016.

Armas Morales, Carlos (2016). «El negocio de las "apps" de taxis y la economía colaborativa: ¿relaciones no laborales o laborales, según los términos contractuales que lo sustentan (caso Perú)?». En Escuela de Postgrado Neumann Business Review, 2 (I).

Auvergnon, Philippe (2016). «Angustias de la uberización y retos que plantea el trabajo digital al derecho laboral» en: Revista Derecho Social y Empresa. Nㅜ 6: 25-42.

Baylos, Antonio (2000). «La huida del Derecho del Trabajo: tendencias y límites de la deslaboralización», en Manuel Alarcón Caracuel y María del Mar Mirón. El trabajo ante el cambio de siglo: un tratamiento mutidisciplinar. España: Marcial Pons.

Baylos, Antonio (1991). Derecho del Trabajo. Modelo para armar. Madrid: Ed. Trotta. 
Caamaño, Eduardo (2004). «El empleo en las fronteras de Derecho del Trabajo (el trabajo autónomo económicamente dependiente)». En: Revista Laboral Chilena, Diciembre 2004: 61 a 71 (primera parte) y enero de 2005: 68 a 74 (segunda parte).

Calvo Gallego, Francisco (2005). «Los trabajadores autónomos dependientes: una primera aproximación». En: Temas laborales: revista andaluza de trabajo y bienestar social, $\mathrm{N}^{\circ} 81$ : 41-78.

Carmelynck y Lyon-Caen (1974). Derecho del Trabajo. Traducción de J. Ramírez. Madrid: Ed. Aguilar.

Cruz Villalon, Jesús, (2000). «Outsourcing y relaciones laborales». En: VV.AA., Descentralización productiva y nuevas formas organizativas del Trabajo, Colección Informes u Estudio. Madrid: Ministerio del Trabajo y Asuntos Sociales.

Dagnino, Emanuele (2015). «Uber law: perspectiva jurídico-laboral de la sharing/on-demand economy». En: Revista Internacional y Comparada de Relaciones Laborales y Derecho del Empleo. Escuela Internacional de Alta Formación en Relaciones y de Trabajo de ADAPT: 131.

Davidov, Guy (2017). «The Status of Uber Drivers: A purposive Approach». En Spanish Labour Law and Employment Relations Journal. Disponible en goo.gl/g4nvhg.

De Stefano, Valerio (2016). «The rise of the just-in-time worforce: On demand work, crowdwork and labour protection in the gig.economy». En Condictions of Work and Employment Series. $\mathrm{N}^{\circ} 71$, OIT, Ginebra. Disponible en goo.gl/rt5441.

Degryse, Cristophe (2016). «Digitalisation of the economy and its impact on labour markets». Bruxelles. Disponible en goo.gl/ANHoCE.

Doménech, Gabriel (2015). «La regulación de la economía colabortiva (El caso "Uber contra el taxi”)». En Revista Ceflegal. Cef, núms. 175-176. Agosto-septiembre 2015: 61-104.

Doz, Javier (2016). «La economía digital desde la perspectiva del Comité Económico y Social Europeo», en ¿Una nueva revolución industrial? Economía digital y trabajo. GS Gaceta Sindical reflexión y debate nueva etapa No 27 DIC. 2016.

Durand, P. (1952). «Naissance d'un droit nouveau: du droit du Travail au Droit de l'activité professionelle». En Droit Social. N 12 Dic. 2010.

Ermida Uriarte, Oscar y Oscar Hernández Álvarez (2002). «Critica de la subordinación, Parte I». En: Revista Laboral Chilena: 67 y ss.

Evans, John y Anna Byhovskaya (2016). «La gestión de la economía digital, hacia un cambio tecnológico abierto, equitativo e inclusivo: una perspectiva sindical». En ¿Una nиeva revolución industrial? Economía digital y trabajo. GS Gaceta Sindical reflexión y debate nueva etapa No 27 DIC. 2016.

Fernandez Brignoni, Hugo (2016). «Las empresas de aplicaciones tecnológicas y el fenómeno "Uber". La llamada "economía disruptiva"». En Derecho Laboral. Tomo LIX: 33-49.

Galiana Moreno, Jesús M. (1998). «Crisis del Contrato de Trabajo». En: Revista de Derecho Social. Ed. Bomarzo N²: 47-66.

Galiana Moreno, Jesús M. (1978). El Contrato de Trabajo en el Derecho Inglés. Barcelona: Bosh.

Gamonal, Sergio y Caterina Guidi (2015). Manual del Contrato de Trabajo. Cuarta Edición. Santiago: Thomson Reuters.

Garmendia, Mario (2016). «La evolución de la tutela jurídica del trabajo». En Revista de Direito do IAP, 1 (1): 25-47. 
Ginés I Fabrellas, Anna y Sergi Gálvez Duran (2016). «Sharing economy vs. Uber economy y las fronteras del Derecho del Trabajo: la (desprotección de los trabajadores en el nuevo entorno digital)». En: Revista para el Análisis del Derecho. Barcelona: InDRet. Disponible en goo.gl/VGpwiu.

Goerlich, José María (2016). «¿Repensar el derecho del trabajo? Cambios tecnológicos y empleo». En ¿Una nueva revolución industrial? Economía digital y trabajo. GS Gaceta Sindical reflexión y debate nueva etapa No 27 DIC. 2016.

Henry, Laura (2012). «Los cambiantes contornos de la relación laboral: la atenuación de las fronteras entre el trabajo dependiente y el trabajo subordinado en contextos de tercerización productiva». En: VIII Jornadas de Sociología de la Universidad Nacional de La Plata «Argentina en el escenario latinoamericano actual: debates desde las ciencias Sociales». (La Plata). Disponible en goo.gl/ShG7Cb.

Hudson, Michel (2016). «¿Estancamiento secular o rebote tecnológico?». En ¿Una nueva revolución industrial? Economía digital y trabajo. GS Gaceta Sindical reflexión y debate nueva etapa $\mathrm{N}^{\circ} 27$ DIC. 2016.

Irureta, Pedro (2013). «Simulación y apariencia en el ámbito laboral: la especial situación del sujeto contratante». En Revista de Derecho de la Pontificia Universidad Católica de Valparaíso, XL: 213-250.

Irureta, Pedro (2007): «La regulación jurídica del trabajo dependiente». En: Ensayos Jurídicos. Universidad Alberto Hurtado, $\mathrm{N}^{\circ} 3$.

Kahn-Freund, Otto (1989). Trabajo y Derecho. España: Ed. Ministerio del Trabajo y Seguridad Social.

Lujan, José (2005). «El ámbito subjetivo del Estatuto de los Trabajadores». En Revista del Ministerio del Trabajo y Asuntos Sociales, 58: 13-40.

Llamosas, Aída (2009). «Las zonas grises en el Derecho Laboral. La prestación del servicio de transporte». En Nomos. Universidad de Viña del Mar, Nº 9: 105-119.

Peliza, Eleonora (2006). «El derecho del trabajo y sus fronteras. La situación latinoamericana. Informalidad y zonas grises». En Panorama Laboral 2006. Oficina Regional de la OIT para América Latina y el Caribe.

Palomeque, Manuel, (2000). El trabajo autónomo y las propuestas de refundación del Derecho del Trabajo. T I. RL.

Palomeque, Manuel y Manuel Álvarez (2003). Derecho del Trabajo. Madrid, $11^{\text {a }}$ Edición, Ed. Centros de Estudio Ramón Areces.

Palomo, Rodrigo (2014). «¿Qué proteger y cómo proteger? Los principios del Derecho del Trabajo como cimientos de una disciplina dinámica». En Ignire. Discusiones Públicas, 5 (1-2).

Pérez Amorós, Francisco (2013). Trabajador autónomo económicamente dependiente en el ordenamiento español: una figura controvertida y contradictoria. Universidad Autónoma de Barcelona.

Pla, Américo (1979). Curso de Derecho Laboral. Montevideo. T.I, V.1.

Prassl, Jeremias and Martin Risak (2017): «Uber, TaskRabbit, \& Co: Platforms as Employeres? Rethinking the legal analysis of crowdwork». En Spanish Labour Law and Employment Relations Journal. Disponible en goo.gl/c89gT8.

Raso Delgue, Juan (2016). «El derecho del trabajo como rama del derecho y sus nuevas fronteras». En Revista Chilena de Derecho del Trabajo y de la Seguridad Social, 7 (13): 1352. 
Raso Delgue, Juan (2016). «La economía virtual: Nuevos retos para el Derecho del Trabajo». En Derecho del Trabajo. N $^{\circ}$ 20/2016, Montevideo, «Universitas» Fundación.

Rojas, Irene (2015). Derecho del Trabajo. Derecho Individual del Trabajo. Santiago: Thomson Reuters.

Supiot, Alain (1998). «Informe Trabajo y empleo». En: Transformation du travail et devenir du droit du travail en Europe. Rapporteur Géneral.

Supiot, Alain (2007). Homo jurídicus. Buenos Aires.

Thayer, William y Patricio Novoa (2016). Manual de Derecho del Trabajo. Sexta Edición. Santiago: Editorial Jurídica de Chile.

Todolí Signes, Adrián (2015). «El impacto de la "Uber economy” en las relaciones laborales: los efectos de las plataformas virtuales en el contrato de trabajo». En Revista Ius Labor, 3: 1-25.

Ugarte, José Luis (2001). «La descentralización productiva: la nueva moda en las relaciones laborales». En Revista Laboral Chilena. Enero 2001: 58.

Ugarte, José Luis (2007). El nuevo Derecho del Trabajo. Santiago: Editorial LexisNexis.

Ugarte, José Luis (2008). La subordinación en el derecho laboral chileno. Santiago: Ed. Legal Publishing.

Walker, Francisco (1960). Introducción al estudio del derecho del trabajo. Santiago: Editorial Jurídica de Chile. 